\title{
䟞|restice
}

\section{Criação e aplicação de um jogo educativo como proposta de ensino aprendizagem a alunos de monitoria na área de anatomia humana geral}

\author{
Creation and implementation of an educational game as a teaching learning proposed \\ monitoring students in the general human anatomy area
}

\section{Carlos Jhone Coelho da Silva ${ }^{1}$, Anairtes Martins de Melo²}

\begin{abstract}
Resumo
Introdução e objetivos: A disciplina de Anatomia Humana é ofertada nos primeiros anos de graduação, e algumas dificuldades são relatadas pelos discentes. Esse estudo propôs elaborar e aplicar um jogo educativo de Anatomia à discentes participantes de um programa de monitoria. Método: Relato de experiência realizado de julho/2016 a julho/2017, período vigente ao Programa de Iniciação Científica e Tecnológica (PICT) do pesquisador no UNIFANOR/WYDEN. A pesquisa constou de cinco fases desde o processo de elaboração até a aplicação do jogo. Resultados: O jogo nomeado Anatomicamente foi elaborado em tabuleiro contemplando os sistemas: esquelético, muscular, nervoso, circulatório, respiratório, digestório e genital masculino/feminino. A aplicação do jogo inferiu que os participantes demonstraram sentimento de ansiedade e quanto ao desempenho analisado, a partir da aplicação do questionário em dois momentos da pesquisa, percebeu-se que os alunos obtiveram uma melhora na pontuação em relação aos acertos das questões. Conclusão: Pode-se considerar que a criação de um jogo educativo é viável como proposta de metodologia ativa lúdica e atraente para o processo de ensino-aprendizagem de Anatomia Humana. Sugerem-se que sejam realizados novos estudos nessa temática, a fim de se ter maior entendimento quanto ao processo de inserção de metodologias ativas no ensino à saúde.
\end{abstract}

A pesquisa foi aprovada pelo Comitê de Ética em Pesquisa da Academia Cearense de Odontologia, Fortaleza-Ceará, sob o número: 62749316.9.0000.5034.

Palavras-Chave: Jogo educativo. Monitoria. Ciências Anatômicas.

\begin{abstract}
Introduction and Objectives: The discipline of Human Anatomy is offered in the early years of graduation and some difficulties are reported by students. This study has proposed drawing up and implementing an educational game Anatomy of the students participating in a monitoring program. Method: Experience report carried out from July/2016 to July/2017, current period to the Scientific and Technological Initiation Program (PICT) of the researcher in UNIFANOR/WYDEN. The survey consisted of five stages from the preparation process to the game application. Results: The game named Anatomically was drafted in contemplating board systems: skeletal, muscular, nervous, circulatory, respiratory, digestive and genital male/female. Application of inferred game participants demonstrated sense of anxiety and for

\footnotetext{
1 Graduado em Fisioterapia. Centro Universitário Faculdades do Nordeste (UNIFANOR). E-mail: jhonefisio@outlook.com.br 2 Mestre em Ensino na Saúde. Universidade Estadual do Ceará (UECE). E-mail: anairtes.melo@unifanor.edu.br Correspondência: Coordenação do Curso de Fisioterapia (UNIFANOR) - R. Antônio Gomes Guimarães, 150 - Papicu, Fortaleza - CE, 60191-195.
} 
performance analysis from the questionnaire in two stages of the research, it is clear that students achieved an improvement in the score the hits of the issues. Conclusion: It can be considered that the creation of an educational game is viable as proposed playful and appealing active methodology to the process of teaching and learning of Human Anatomy. It is suggested to be carried out further studies in this subject, in order to have better understanding about the process of inserting active methods in teaching health.

Keywords: Educational Game. Monitoring. Anatomical Sciences.

\section{Introdução}

As disciplinas anatômicas são ofertadas nos primeiros anos dos cursos de graduação em saúde. Muitos dos estudantes apresentam dificuldades para o aprendizado das estruturas anatômicas por motivos variados ${ }^{1}$.

A partir da percepção do pesquisador, discente do curso de Fisioterapia e monitor da disciplina de anatomia humana dos cursos de saúde da instituição de ensino superior (IES) deste estudo, uma das principais dificuldades relatadas por discentes matriculados são referentes à memorização dos termos presentes no repertório das estruturas humanas estudadas e, ainda, dificuldades relacionadas à técnica de estudo mais apropriada. Supõem, portanto, que estas dificuldades se referem ao fato de serem discentes recém-chegados ao nível superior e não acostumados com a grande demanda de conteúdos e especificidades do ensino superior em saúde.

Na UNIFANORIWYDEN, a disciplina de Anatomia Humana Geral é ofertada para todos os cursos da saúde nos primeiros períodos da graduação. Os alunos matriculados estudam os principais sistemas constituintes do corpo humano, adquirindo conhecimentos que são avaliados através de provas teóricas e práticas.

A monitoria consiste em uma atividade acadêmica de natureza complementar, na qual o discente-monitor tem a oportunidade de desenvolver e ampliar os conhecimentos adquiridos na academia por meio do apoio ao docente na condução da disciplina².

Define monitoria como uma modalidade específica, estabelecida dentro do princípio de vinculação exclusiva às necessidades de formação acadêmica do aluno de graduação e pós-graduação e inserida no planejamento das atividades de ensino, pesquisa e extensão dos cursos $^{3}$.

Na IES desta pesquisa, a monitoria voluntária é um programa das coordenações acadêmicas dos diversos cursos de graduação, que selecionam alunos para exercerem dentro da carga horária total de 60 horas/semestrais, distribuídas em 6 horas/semanais, 
atividades de auxílio aos alunos daquelas disciplinas.

Além de promover um enriquecimento da vida acadêmica do discente, a atividade de monitoria possibilita, por meio da relação de cooperação existente entre docente e monitor, o aprimoramento da qualidade de ensino da disciplina, uma vez que favorece a adoção de novas metodologias de ensino, bem como impulsiona o exercício da pesquisa acadêmica, permitindo uma contínua associação entre teoria e prática ${ }^{2}$.

Algumas IES já perceberam a importância de estimular a criação de novos métodos de ensino que diferem do modo tradicional de aulas expositivas, não para substituí-lo, mas para complementar o modelo já existente. Esta iniciativa é de extrema importância para cursos da área da saúde, que contam com conteúdos práticos, neste caso, em especial, a Anatomia Humana 4 .

O grande desafio é a crescente busca por metodologias que possibilitem uma práxis pedagógica capaz de ultrapassar os limites do treinamento puramente técnico e tradicional, para efetivamente alcançar a formação do sujeito como um ser ético, histórico, crítico, reflexivo, transformador e humanizado.

Para o Ministério da Educação (MEC), as Diretrizes Curriculares Nacionais (DCN) estabelecem que o perfil dos egressos de um curso compreenderá uma sólida formação técnica, científica e profissional geral que 0 capacite a absorver e a desenvolver novas tecnologias estimulando a sua atuação crítica e reflexiva, criativa na identificação e resolução de problemas, considerando seus aspectos políticos, econômicos, sociais, ambientais e culturais, com visão ética e humanística, em atendimento às demandas da sociedade ${ }^{5}$.

A metodologia ativa é uma concepção educativa que estimula processos construtivos de ação-reflexãoação ${ }^{6}$.

Produzir aprendizagem ativa a partir da utilização de jogos educativos provoca no alunato uma aprendizagem que não vem especificamente do jogo em si, mas do que é gerado a partir das intervenções e dos desafios propostos aos participantes do jogo. A atividade educativa mediada por um jogo proporciona ao indivíduo a vivência de situações-problema que possibilitam a investigação do pensamento e a busca por respostas, portanto a aquisição de uma nova aprendizagem, pois não é possível a resolução de problemas sem aprender ${ }^{7}$.

Ainda, autores enfatizam que os jogos educativos direcionados para 0 ensino auxiliam a construção e o aprimoramento do aprendizado, através de atividades lúdicas, e, mais além, desenvolvem a afeição atuando nos laços de amizade e cordialidade; a socialização, estimulando o trabalho em equipe; a motivação, que envolve 0 interesse em descobrir, o desafio e, por fim, desenvolve a capacidade de criar $^{8}$. 
Justifica-se a realização deste estudo baseado na experiência com monitoria, onde se avistou a necessidade de produção de um recurso de aprendizagem no ambiente acadêmico que estimule e proporcione novas formas e métodos de estudo aos acadêmicos, favorecendo a construção de novos conhecimentos e a memorização dos conteúdos e das nomenclaturas anatômicas. Refere-se que 0 jogo educativo, além de lúdico, pode ser utilizado coletivamente em sessões educativas durante o cronograma da disciplina.

A partir do exposto, o presente estudo objetiva desenvolver um jogo educativo com conteúdos da disciplina de Anatomia Humana Geral em uma instituição de ensino superior e, ainda, aplicar o jogo educativo desenvolvido a um grupo de discentes que frequentem a monitoria da disciplina de Anatomia Humana Geral e analisar o desempenho teórico dos discentes que vivenciaram a aplicação do jogo, a partir de um questionário aplicado antes e após a partida teste.

\section{Métodos}

Trata-se de um relato de experiência realizado no segundo semestre do ano de 2016 e no primeiro semestre do ano de 2017 em uma IES nomeada UNIFANOR/WYDEN, localizada no bairro Dunas da cidade de Fortaleza Ceará - nordeste do Brasil, nas dependências do laboratório de Anatomia Humana.

A população da pesquisa constou dos discentes matriculados na disciplina de Anatomia Humana, que frequentavam a monitoria realizada no contra turno da disciplina, no total de 24 alunos. Já a amostra, adquirida por conveniência, constou de 12 alunos (50\% da população) inclusos por apresentarem maior frequência nas atividades de monitoria em todo o cronograma. Foram exclusos da pesquisa os alunos impossibilitados de comparecer nos horários da partida teste (aplicação do jogo) e aqueles que por algum motivo, não responderam ao questionário avaliativo aplicado antes e após a partida teste: na terceira e quinta fase da pesquisa.

A pesquisa constou de cinco fases, descritas abaixo:

1. Pesquisa em sítios bibliográficos digitais no intuito de visualizar as propostas pedagógicas no ensino de anatomia humana, no que se refere a jogos educativos. A pesquisa foi realizada com as palavras chaves: anatomia, educação, ensino, métodos e aprendizagem, nas bibliotecas virtuais SciELO; EBSCOHost; Google Acadêmico.

2. Elaboração do jogo educativo que abordou temas sobre os sistemas orgânicos estudados na disciplina de Anatomia Humana, a saber: sistemas esquelético, muscular, nervoso, 
circulatório, respiratório, digestório e genital masculino/ feminino.

3. Aplicação de um questionário avaliativo composto por oito questões, com temáticas abordadas no jogo. Esse questionário avalia os domínios de conhecimento quanto a localização e o funcionamento das estruturas anatômicas, e ainda a escrita das nomenclaturas anatômicas dos sistemas orgânicos. Ressalta-se que o questionário da pesquisa foi previamente avaliado pelos docentes da disciplina de Anatomia Humana Geral.

4. Na quarta fase foi realizada a partida teste, na qual os alunos foram convocados a participar com data e horário programados.

5. Na quinta fase da pesquisa o mesmo questionário avaliativo utilizado na fase 3 foi reaplicado à amostra da pesquisa, com o intuito de analisar a quantidade de acertos nas questões respondidas.

O estudo foi aprovado pelo Comitê de Ética em Pesquisa da Academia Cearense de Odontologia localizado no bairro São João do Tauape, FortalezaCeará com número do parecer: 62749316.9.0000.5034. Todos os participantes assinaram 0 Termo de Consentimento Livre e Esclarecido.

\section{Resultados}

Os achados do levantamento bibliográfico advindos da primeira fase da pesquisa foram pontuados a seguir:

- O primeiro estudo ${ }^{9}$, intitulado Avaliação de estudantes de enfermagem sobre o jogo educacional de anatomia e fisiologia digestória humana, objetivou avaliar o impacto da tecnologia criada para uma futura implementação do mesmo, ficou claro, segundo os alunos participantes da pesquisa, que estratégias que estimulem o ensino e aprendizagem são importantes para a facilitar e conduzir os estudos na formação profissional.

- Outro artigo ${ }^{10}$, propôs inserir um jogo na rotina de estudantes do ensino médio, com a finalidade de estimular um pensamento crítico e reflexivo. No final dos testes, pode-se evidenciar a contribuição significativa da metodologia de ensino, através de pesquisas quantitativas e qualitativas.

- $\mathrm{Na}$ pesquisa intitulada: Desenvolvimento e avaliação de um sistema hipermídia, que integra conceitos básicos, foi desenvolvido um sistema com conteúdos de mais de uma disciplina da grade curricular do curso de Fisioterapia. Neste estudo, pode-se reconhecer que 0 material desenvolvido não pode resolver, isoladamente, problemas pedagógicos das disciplinas, sendo este estudo um indicador de que o quadro geral possa 
ser transformado a partir de iniciativas e de pesquisas voltadas objetivamente para encontrar soluções adequadas ${ }^{11}$.

- Já em uma dissertação ${ }^{12}$, foi analisado o processo de aprendizagem de alunos de uma escola pública sobre a morfologia humana, a partir da utilização de modelos anatômicos alternativos. Além de ser observado como um método inovador, pode-se destacar a escassez da utilização, a confecção de baixo custo e sua aplicabilidade que facilita no processo ensino aprendizagem, o que se torna semelhante a outro estudo ${ }^{13}$ que, mesmo apresentando dificuldades iniciais com nomes de estruturas anatômicas e fisiológicas, apresentaram-se conclusões semelhantes a partir das percepções dos alunos participantes.

- Observaram-se semelhanças entre dois estudos ${ }^{4,1}$, quando concluíram que jogos educacionais como método didático é uma forma diferenciada de complementar os métodos tradicionais amplamente utilizados, apresentado maior eficácia na aquisição de conhecimentos, quando comparado às aulas expositivas tradicionais.

Os jogos educativos possibilitam ao aluno aprender de forma natural, prazerosa e dinâmica, porque traz desafios e estimulam a busca dos conhecimentos, além de oferecer um maior envolvimento social entre os alunos, bem como a formação de conceitos éticos, de solidariedade, de regras, de trabalho em grupo, de respeito mútuo, entre outros ${ }^{14}$.

$\mathrm{Na}$ segunda etapa do estudo, foi construído o jogo em modelo de tabuleiro, confeccionado em papel couchê colorido no tamanho de $50 \mathrm{~cm} \times 50 \mathrm{~cm}$, contendo figuras relacionadas a cada sistema orgânico, além de uma estrutura semelhante a uma caixa ao meio do tabuleiro onde serve para acolher quatro bolinhas de plástico coloridas, utilizadas pelos jogadores no decorrer do jogo (FIGURA 01).

Figura 01: caixa no meio do tabuleiro para acolher as bolinhas dos jogadores.

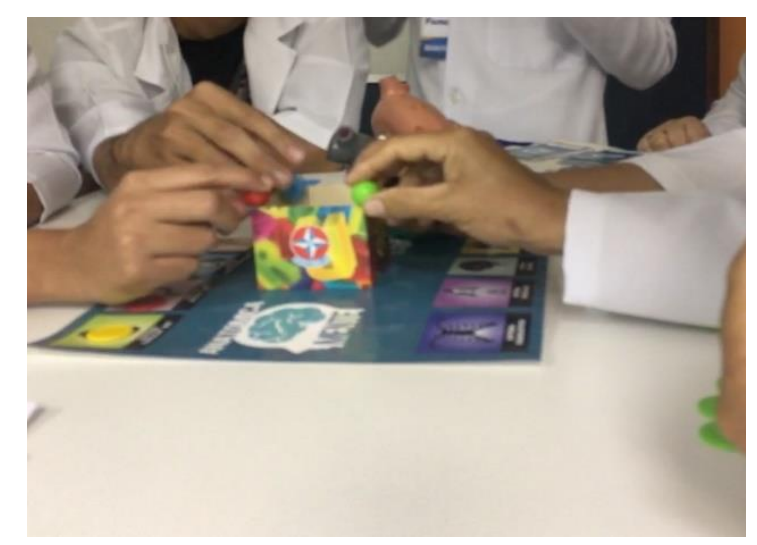

Fonte: acervo da pesquisa, 2018.

Tem-se ainda, 10 fichas plásticas coloridas: vermelha, amarela, azul e verde que são utilizadas pelo jogador para a indicação dos acertos. Estas fichas são colocadas sobre a gravura do tabuleiro, que corresponde ao sistema orgânico, no qual foi respondido de forma correta pelo jogador.

O nome dado ao jogo foi AnatomicaMente, pois faz alusão à disciplina de Anatomia Humana e ao 
processo de mentalização, ou seja, a mente humana. Além da criação do nome e do layout do tabuleiro, foram elaboradas oito cartas para cada sistema orgânico com perguntas relacionadas à localização de estruturas, funcionalidade e nomenclaturas anatômicas (FIGURA 02).

Figura 02: cartas dos sistemas contendo as perguntas.

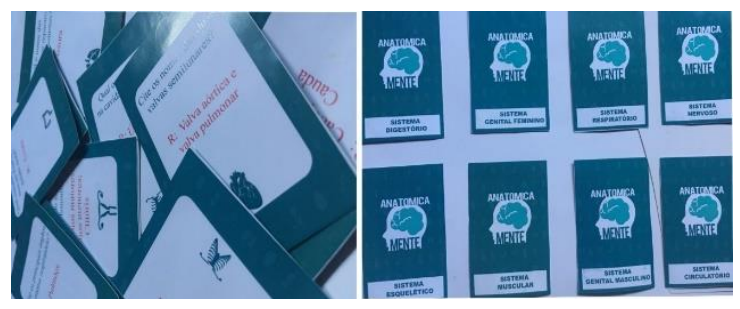

Fonte: acervo da pesquisa, 2018.

Na terceira fase do estudo aplicou-se - questionário da pesquisa. Essa aplicação foi realizada em um só dia compondo o cronograma da monitoria.

A quarta fase constou da partida teste, em dia marcado previamente com os alunos do estudo. Nesta fase inicialmente, as regras do jogo foram explicadas, a saber: cada partida contou com 4 jogadores onde cada jogador no início da partida recebeu 10 fichas com uma única cor e uma bolinha plástica na mesma cor das fichas. O monitor escolheu um dos sistemas que compõe o jogo e retirou uma das cartas para ler a pergunta. Após o monitor lançar a pergunta referente ao sistema da vez, deu o sinal de valendo, os jogadores que sabiam a resposta, jogaram a bolinha na caixa, onde apenas uma bolinha entra no centro dessa caixa, determinando ao participante, a chance de responder à pergunta. A resposta foi avaliada pelo monitor junto com os alunos, sendo considerada correta, o participante que respondeu ganhou um ponto, colocando uma das suas fichas na mesma cor da bolinha, sobre a gravura do sistema que está no tabuleiro.

Foram contabilizadas as fichas de cada jogador que permaneceram no tabuleiro, vencendo, assim, aquele grupo que obteve o maior número de acertos.

Os resultados da pesquisa obtidos na partida com jogo, foram captados das anotações presentes em diário de campo dos pesquisadores.

Percebeu-se que os alunos demonstravam sentimento de ansiedade para a vivência da atividade. Todos os alunos participaram das partidas, mesmo aqueles que não estavam na vez de jogar, pois, atentos, acompanhavam os colegas fazendo torcida e estimulando-os a responder as perguntas corretamente.

No início do jogo os alunos se mostravam confusos, contudo, conforme jogavam, as regras ficavam mais claras, o que os incentivou a continuidade do desenvolvimento das atividades, com animação e um maior aproveitamento, quando relacionado ao aprendizado.

Todos os grupos conseguiram terminar pelo menos uma rodada do jogo. Os aplicadores, monitores da disciplina, atuaram como mediadores durante a realização das partidas. Os conhecimentos dos alunos foram testados para 
estabelecer as associações de cartas com os sistemas e as estruturas aos quais as perguntas se relacionavam.

Figura 03: participação dos alunos durante as partidas

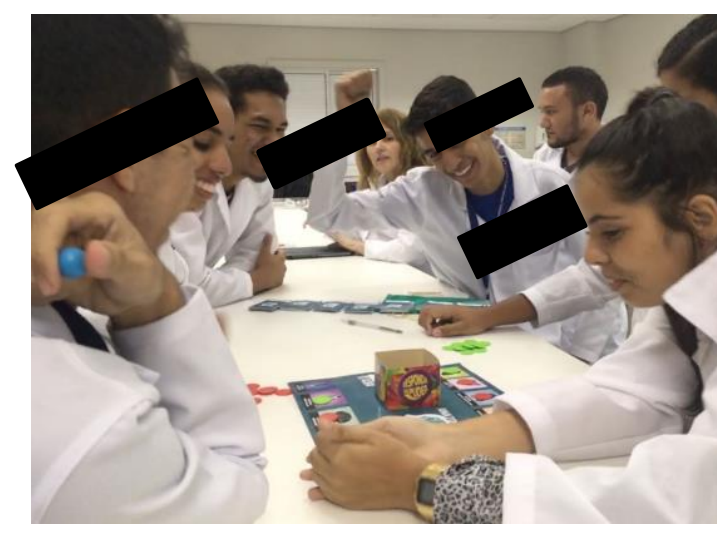

Fonte: acervo da pesquisa, 2018. (A fotografia foi alterada para preservar a imagem dos pesquisados)

A apreciação positiva de um jogo didático pelos participantes depende de alguns aspectos, como características do material, ludicidade, aprendizagem de conteúdos já conhecidos, criatividade na dinâmica do jogar e direcionamento das regras, além de interação dos participantes ${ }^{7}$.

$\mathrm{Na}$ última fase da pesquisa, foi reaplicado o mesmo questionário com 0 objetivo de analisar o desempenho dos alunos quanto as respostas após a aplicação do jogo.

Os resultados evidenciaram uma melhora no desempenho dos alunos. Os resultados foram obtidos a partir da análise quantitativa de acertos às perguntas presentes no questionário aplicado antes da partida (com o jogo criado) e depois, como mostra a tabela a seguir:
Tabela 1: pontuação comparativa das duas aplicações do questionário ao Grupo Intervenção

\begin{tabular}{|c|c|c|}
\hline $\begin{array}{c}\text { Alunos } \\
\text { Grupo }\end{array}$ & $\begin{array}{c}\text { Pontos obtidos } \\
\text { na primeira } \\
\text { aplicação do } \\
\text { questionário } \\
\text { avaliativo }\end{array}$ & $\begin{array}{c}\text { Pontos obtidos } \\
\text { no reteste do } \\
\text { questionário } \\
\text { avaliativo }\end{array}$ \\
\hline A1 & 9,5 & 10,0 \\
\hline A2 & 7,5 & 8,5 \\
\hline A3 & 7,0 & 9,0 \\
\hline A4 & 9,0 & 10,0 \\
\hline A5 & 7,0 & 7,5 \\
\hline A6 & 8,0 & 9,5 \\
\hline A7 & 8,0 & 10,0 \\
\hline A8 & 6,5 & 7,5 \\
\hline A9 & 6,5 & 8,0 \\
\hline A10 & 9,0 & 9,0 \\
\hline A11 & 9,5 & 10,0 \\
\hline A12 & 8,5 & 10,0 \\
\hline
\end{tabular}

Fonte: acervo da pesquisa, 2018

Como complemento à pesquisa, foi realizada a escuta de opiniões dos alunos em relação à proposta do jogo educativo, em que se verificou que o aspecto lúdico proporcionado pelo jogo é bastante motivador. Além disso, alguns dos alunos informaram que 0 jogo contribuiu para a maior compreensão da Anatomia Humana, pois ajudou a se lembrarem dos conceitos que já sabiam e/ou esclareceram dúvidas.

Esses resultados estão de acordo com outros estudos que evidenciam o uso de metodologias ativas, como jogos educativos, responsáveis pela melhora na capacidade de adquirir e guardar informações em comparação com métodos de ensino tradicionais. 
A literatura discute a importância da construção, pelo educador, de outra concepção de educação, ressaltando a necessidade de se ter clareza sobre os limites e os problemas de metodologias expositivas, como o baixo nível de interação sujeito-objeto, de conhecimento e a contribuição na formação de um sujeito passivo e não crítico. Assim, considera-se que, além de construir o conhecimento, é necessário mobilizar 0 sujeito para 0 conhecimento e estimular a sua elaboração e síntese.

\section{Conclusão}

A partir dos resultados apontados nessa pesquisa, pode-se considerar que a proposta pedagógica de ensinoaprendizagem de Anatomia Humana com jogos educativos vem sendo planejada e trabalhada como proposta significativa ao aprendiz.

O uso das metodologias leves e atraentes contribui no processo de desenvolvimento e refinamento do ensino, demonstrando-se relevante a inserção desses recursos educacionais como estratégias no desenvolvimento do processo de ensino e aprendizagem em Anatomia Humana.

Percebeu-se ainda, na fase de aplicação do jogo, que ocorreu uma dificuldade inicial dos discentes em relação às regras na dinâmica do jogo, portanto se recomenda a elaboração de um folheto com as regras impressas para uma melhor e possível consulta durante novas partidas do jogo.

Sugerem-se que sejam realizados novos estudos nessa temática, a fim de se ter maior entendimento quanto ao processo de inserção de metodologias ativas no ensino à saúde.

\section{Referências}

1. Braz PRP. Método didático aplicado ao ensino da anatomia humana. Anuário da Produção Acadêmica Docente. 2014;3(4):303-310.

2. Lins D. Ser monitor. 2016. Acesso em: 20/02/2019. Disponível em:

http://www.mauricionassau.com.br/instituc ionais/faculdade/index.php?artigo/listar/21 5

3. Soares MDAA. Santos K F. A monitoria como subsídio ao processo de ensino-aprendizagem: o caso da disciplina administração financeira no CCHSA-UFPB. Anais do XI Encontro de Iniciaçao a Docencia, 2017;2(1):1-2. 4. Weintraub M. Hawlitschek P. João SMA. Jogo educacional sobre avaliação em fisioterapia: uma nova abordagem acadêmica. Revista Fisioterapia e Pesquisa. 2015;18(3):280-286.

5. Gemignani EYMY. Formação de professores e metodologias ativas de ensino-aprendizagem: ensinar para a compreensão. Revista Fronteiras da Educação. 2013;1(2): 20-27.

6. Freire P. Pedagogia do Oprimido. São Paulo: Paz e Terra; 2006.

7. Melo AM. Utilização de jogos educativos como proposta de ensino e aprendizagem na fisioterapia respiratória. Fortaleza: Universidade Estadual do Ceará, 2014. Dissertação de Mestrado Profissional em Ensino na Saúde.

8. Saidelles APF. Cruz LC. Kirchner RM. Pivotto, OL. Santos DS. Santos NR Z. Jogo Didático como auxiliar para o aprendizado em química. 2016. Acesso em 20/02/2019. Disponível em: http://jne.unifra.br/artigos/4745.pdf 
9. Dias J D. et al. Avaliação de estudantes de enfermagem sobre jogo educacional de anatomia e fisiologia digestória humana. Nuevas Ideas en Informática Educativa TISE, 2015;11(1):689-694.

10. Ferreira CN. Maroto GS. Costa M R C D. Metodologias inovadoras no ensino da anatomia humana como forma de construção do pensamento crítico reflexivo de alunos do ensino médio. Anais do Encontro Internacional de Formação de Professores e Fórum Permanente de Inovação Educacional, 2016;9(1).

11. Rezende F. Garcia MAC. Cola C S

D. Desenvolvimento e avaliação de um sistema hipermídia que integra conceitos básicos de Mecânica, Biomecânica e Anatomia humana. Revista Investigações em Ensino de Ciências, 2016;11(2):239251.

12. Silva Junior EX. Avaliação do uso de modelos anatômicos alternativos para o ensino-aprendizagem da anatomia humana para alunos do ensino fundamental de uma escola pública da cidade de Petrolina, PE. Petrolina:

Universidade Federal Rio Grande do Sul, 2015. Dissertação de Mestrado em Educação.

13. Alves TA. Falcão LS. Souza AT. Amaral TS. Lima SP. Carvalho, TB. Fisio card game: um jogo didático para o ensino da fisiologia na educação básica. Revista de Ensino de Bioquímica. 2016;14(1):99-117.

14. Nicolleti AAM. et al.; Aprender brincando: utilização de jogos, brinquedos e brincadeiras como recurso pedagógico. Revista de Divulgação Técnico-Científica do ICPG. 2014;2(5):91-94. 


\section{Como citar este artigo}

Coelho CJ. Melo AM. Criação e aplicação de um jogo educativo como proposta de ensino aprendizagem a alunos de monitoria na área de anatomia humana geral, volume 4, n.2. Editor responsável: Luiz Roberto de Oliveira. Fortaleza, mês e ano, p.35-45. Disponível em: http://periodicos.ufc.br/resdite/index. Acesso em "dia/mês/ano".

Data de recebimento do artigo: 24/09/2019

Data de aprovação do artigo: 09/11/2019

RE. SAÚD. DIGI. TEC. EDU., Fortaleza, CE, v.4, n.2, p.35-45, ago./dez. 2019. 